\title{
HIGH ALTITUDE PULMONARY EDEMA (HAPE)
}

\author{
Mariyatul Khiptiyah ${ }^{1}$, Teguh Rahayu Sartono ${ }^{1}$, Indrastuti Normahayu², Wiwi Jaya ${ }^{3}$ \\ ${ }^{1}$ Departement of Pulmonology and Respiratory Medicine Faculty of Medicine Brawijaya University, Dr. Saiful Anwar \\ Hospital, Malang \\ 2 Departement of Radiology Faculty of Medicine Brawijaya University, Dr. Saiful Anwar Hospital, Malang \\ ${ }^{3}$ Departement of Anaesthesia and Intensive Care Medicine Faculty of Medicine Brawijaya University, Dr. Saiful Anwar \\ Hospital, Malang
}

\begin{abstract}
Introduction: High altitude pulmonary edema (HAPE) is one of the acute, severe, noncardiogenic disease that could be life threatening, occurs upon either the first or subsequent exposure to high altitude. It is triggered by a shortage of oxygen after ascending high altitude. The most effective therapeutic approach for HAPE is to immediately descend from high altitude and to give oxygenation, maintaining arterial saturation over $90 \%$, as well as letting the patient rest from strenuous physical activity. The use of portable hyperbaric chamber is also deemed effective in certain circumstance, and nifedipine can also be used to treat HAPE, even as additional treatment in condition that the patients had yet to descend and oxygenation is still not administrable.
\end{abstract}

Case Report: We reported a case at Rs. Dr. Saiful Anwar, a 23-year-old male with High Altitude Pulmonary Edema (HAPE). Diagnosis established from anamnesis, physical examination, and laboratory tests. Patient complained shortness of breath when climbing Mt. Semeru, in which the patient reached an altitude of $2700 \mathrm{mdpl}$ in 2 days. Physical examination showed oxygen saturation 46-49\% with NRBM $10 \mathrm{lpm}$, and rhonchi breath sound in all lung areas. Laboratory examination showed leukocytosis, blood gas analysis showed hypocarbia, severe hipoxemia, metabolic acidosis, and type I respiratory failure. Ches XRay showed wide, irregular infiltrate in both lungs. Based on those, the patient was diagnosed with HAPE. In this case, the patient was given oxygenation.

Conclusion: In this case, the patient was diagnosed with HAPE based on anamnesis, physical examination, and laboratory tests. Oxygenation given to the patient improved his condition.

Keywords: High altitude disease, Acclimatization, Pathophysiology, Management and treatment.

MRJ 2021; 03(01): 127-132

*Corresponding author:

Mariyatul Khiptiyah (m.khiptiyah99@gmail.com)

Departement of Pulmonology and Respiratory Medicine Medical Faculty of Brawijaya, Dr. Saiful Anwar Hospital, Malang 


\section{Background}

High Altitude Pulmonary Edema (HAPE) is a severe type of high-altitude disease, manifests as a rapid-onset condition that can progress and change quickly. HAPE is also known as one of the most common cause of death from altitude. The incidence rate of HAPE varies significantly between China and the others country reports, for example it ranges between $0.5 \%$ and $9.9 \%$. The incidence rate is higher in kids and teenagers than in adult. For instance, data collected from Peru reports that the incidence rate was $10 \%$ in children aged 2$12,17 \%$ in teens aged $13-20$, and $3 \%$ in adults over $21 .{ }^{1}$

High Altitude Pulmonary Edema is a form of high altitude idiopathy that occurs upon either the first or subsequent exposure to high altitude. It is triggered by a shortage of oxygen and certain other predisposing factors, all of which lead to a sudden increase in pulmonary arterial pressure, increase in lung blood volume, disturbance of pulmonary circulation, and leakage of fluid in microcirculation into the pulmonary interstitium and alveoli. The clinical symptoms of this condition include dyspnea and hacking cough. ${ }^{1}$ HAPE is characterized by loss of stamina, dyspnea, and dry cough with exertion, followed by dyspnea at rest, rales, cyanosis, cough, and pink, frothy sputum.$^{2}$ On Physical examination, persons with HAPE have tachycardia, tachypnea, low-grade fever, and inspiratory crackles on lung auscultation, which are typically bilateral but may be unilateral in early HAPE, often heard in the right middle lobe. ${ }^{3}$

On Chest radiography, HAPE is characterized by patchy bilateral alveolar infiltrates that may be unilateral in the right hemithorax in early HAPE. ${ }^{3}$ In several cases of HAPE that requires hospitalization, in late stage of HAPE, a more homogeneous pulmonary infiltrate may be found, indicating development of infiltrate distribution in line with increasing severity.

Leukocyte count is typically normal or mildly increased; about $40 \%$ patients have a count over $1000 / \mathrm{mm}^{3}$. The highest count recorded based on studies was $6400 / \mathrm{mm}^{3}$. The neutrophilic granulocyte count also increases mildly. If the leukocyte and neutrophilic granulocyte counts continue to rise, it usually indicates concurrent infection. ${ }^{1}$

In remote settings, where oxygen and medical expertise may be unavailable, immediate descent is a lifesaving measure after diagnosing HAPE. Delaying descent while HAPE progresses or waiting for rescue personnel to initiate evacuation can prove fatal. Descents of 1500 to 3000 feet should be adequate for a rapid recovery. On 
difficult terrain or in weather conditions that hamper efforts to descend, oxygen administration (or hyperbaric therapy) is a lifesaving measure. ${ }^{4}$

\section{Case Report}

A 23-years-old male, admitted with shortness of breath when climbing the Semeru mountain on August 16, 2017, without doing acclimatization. In 2 days of hiking, the patient had already reached the altitude of $2700 \mathrm{mdpl}$. On the altitude of $2600 \mathrm{mdpl}$, the patient felt headache, but still pushed himself to continue climbing. On the altitude of $2700 \mathrm{mdpl}$, the patient complained shortness of breath, fever, accompanied by cough, sometimes producing blood. Three days prior to climbing, patient had just recovered from fever, coughs, and cold he suffered for 1 week.

Patient was evacuated and was given treatment in Sumber Sentosa Hospital with initial oxygen saturation 46-49\%. Patient was given oxygenation and underwent laboratory examination and chest radiography. Patient was referred to Saiful Anwar Hospital after 1 day admission without improvement in his condition.

Physical examination revealed that the patient is obese (BMI $32 \mathrm{~kg} / \mathrm{m}^{2}$ ), he looked severely ill and restless. His breath frequency increased $(60 \mathrm{x} / \mathrm{min})$ and his oxygen saturation was $90 \%$ with NRBM 10 lpm. Lung examination revealed decreased stem fremitus in all lung area, and rhonchi was heard in all lung area.

Laboratory examination, showed that leukocyte count is $29.250 / \mu \mathrm{L}$ and differential count of neutrophyl is $87,3 \%$ while lymphocyte is decreased $(6,5 \%)$. There was also inrease in ureum $(62,50$ $\mathrm{mg} / \mathrm{dL})$, creatine $(1,41 \mathrm{mg} / \mathrm{dL})$, dan lactic acid (3,7 mmol/dL). Radiology examination (Figure 1,2,3,4) showed:

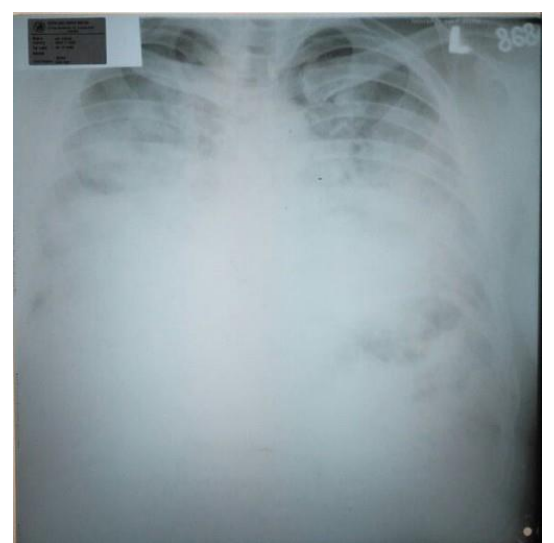

Figure 1. Chest X Ray PA position on July 19, 2017 showed severe cardiogenic pulmonary edema edema, pneumonia

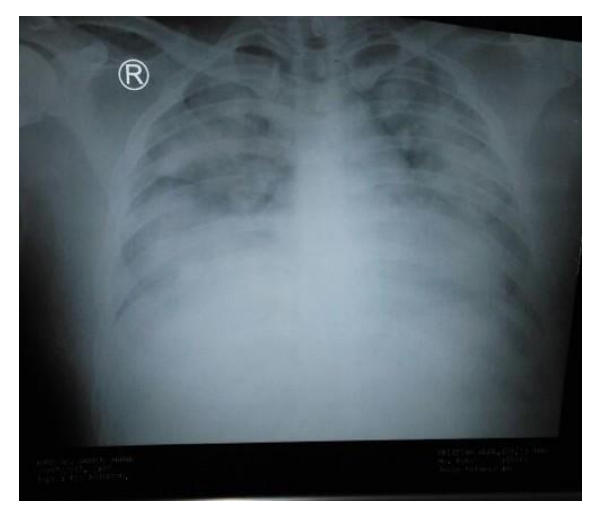

Figure 2. Chest $X$ Ray PA position on July 20 , 2017, compared to July 19, 2017, showed decreased pulmonary edema, pneumonia 


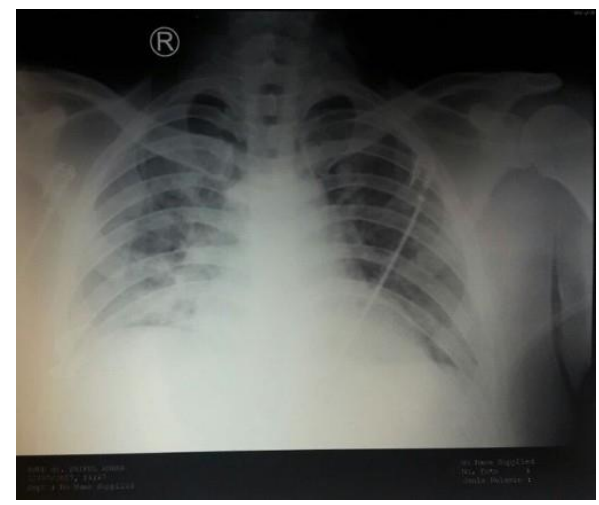

Figure 3. Chest X Ray PA position on July 22, 2017 dibandingkan 19 Juli 2017 showed decreased pulmonary edema, pneumonia

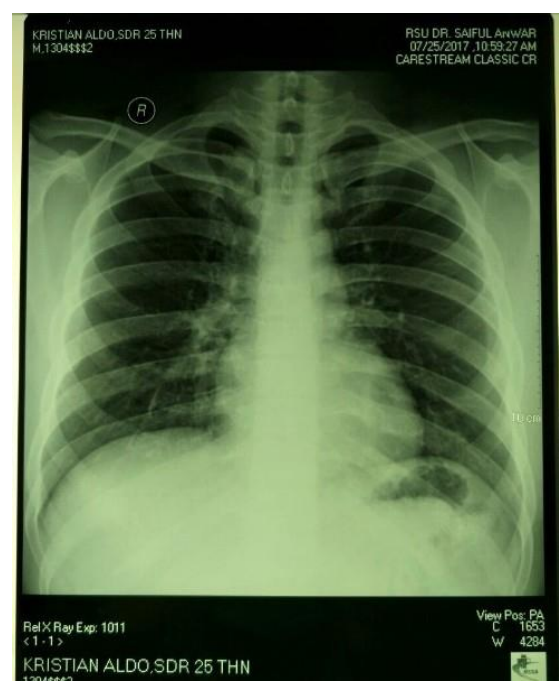

Figure 4. Chest X Ray PA position on July 25, 2017 showed normal lung

Blood gas analysis examination (table 1, 2, 3, 4, 5) showed :

Table 1. Blood Gas Analysis on July 19, 2017; 17.08 patient on NRBM $10 \mathrm{lpm}$

\begin{tabular}{llll}
\hline & Result & Unit & Normal Value \\
\hline $\mathrm{pH}$ & 7.42 & & $7.35-7.45$ \\
$\mathrm{pCO}_{2}$ & 27.5 & $\mathrm{mmHg}$ & $35-45$ \\
$\mathrm{pO}_{2}$ & 42 & $\mathrm{mmHg}$ & $80-100$ \\
$\mathrm{HCO}_{3}$ & 17.9 & $\mathrm{mmol} / \mathrm{L}$ & $21-28$ \\
$\mathrm{BE}$ & -6.8 & $\mathrm{mmol} / \mathrm{L}$ & $-3-+3$ \\
$\mathrm{Sat}$ & 79 & $\%$ & $>95$
\end{tabular}

Before oxygenation: Severe hypoxemia. After oxygenation: Hypocarbia, Severe Hypoxemia, Metabolic acidosis, type I respiratory failure
Table 2. Blood Gas Analysis on July 19, 2017; 19.55 patient on NRBM $10 \mathrm{lpm}$

\begin{tabular}{lllll}
\hline & Result & Unit & Normal Value \\
\hline $\mathrm{pH}$ & 7.41 & & $7.35-7.45$ & \\
$\mathrm{pCO}_{2}$ & 30.2 & $\mathrm{mmHg}$ & $35-45$ \\
$\mathrm{pO}_{2}$ & 78.8 & $\mathrm{mmHg}$ & $80-100$ \\
$\mathrm{HCO}$ & 19.5 & $\mathrm{mmol} / \mathrm{L}$ & $21-28$ \\
$\mathrm{BE}$ & -5.3 & $\mathrm{mmol} / \mathrm{L}$ & $-3-+3$ & \\
Sat & & & \\
& 95.3 & $\%$ & $>95$ & \\
\hline Before & oxygenation: & Severe & hypoxemia. After
\end{tabular}
oxygenation: Hypocarbia, Mild Hypoxemia, Metabolic acidosis, type I respiratory failure

Table 3. Blood Gas Analysis on July 20, 2017; 10.29 patient on NRBM $10 \mathrm{lpm}$

\begin{tabular}{lllll}
\hline & Result & Unit & Normal Value & \\
\hline $\mathrm{pH}$ & 7.47 & & $7.35-7.45$ & \\
$\mathrm{pCO}_{2}$ & 31.9 & $\mathrm{mmHg}$ & $35-45$ & \\
$\mathrm{pO}_{2}$ & 63.7 & $\mathrm{mmHg}$ & $80-100$ & \\
$\mathrm{HCO}_{3}$ & 23.3 & $\mathrm{mmol} / \mathrm{L}$ & $21-28$ \\
$\mathrm{BE}$ & -0.7 & $\mathrm{mmol} / \mathrm{L}$ & $-3-+3$ & \\
Sat $\mathrm{O}_{2}$ & 93.5 & $\%$ & $>95$ & \\
\hline Before & oxygenation: Severe hypoxemia. After
\end{tabular}
oxygenation: moderate Hypoxemia, Respiratory Alkolosis partially compensated, type I respiratory failure

Table 4. Blood Gas Analysis on July 20, 2017; 19.30 patient on NRBM $10 \mathrm{lpm}$

\begin{tabular}{cccc}
\hline & Result & Unit & Normal Value \\
\hline $\mathrm{pH}$ & 7.46 & & $7.35-7.45$ \\
$\mathrm{pCO}_{2}$ & 39.1 & $\mathrm{mmHg}$ & $35-45$ \\
$\mathrm{pO}_{2}$ & 57.2 & $\mathrm{mmHg}$ & $80-100$ \\
$\mathrm{HCO}_{3}$ & 27.8 & $\mathrm{mmol} / \mathrm{L}$ & $21-28$ \\
$\mathrm{BE}$ & 3.7 & $\mathrm{mmol} / \mathrm{L}$ & $-3-+3$ \\
$\mathrm{Sat} \mathrm{O}$ & 90.4 & $\%$ & $>95$ \\
\hline Oa & &
\end{tabular}

Before oxygenation: Severe hypoxemia. After oxygenation: Moderate Hypoxemia, Metabolic Alkalosis partially compensated, type I respiratory failure

Tabel 5. Blood Gas Analysis on July 21, 2017; 09.25 patient on NRBM $10 \mathrm{lpm}$

\begin{tabular}{cccc} 
& Result & Unit & Normal Value \\
\hline $\mathrm{pH}$ & 7.47 & & $7.35-7.45$ \\
$\mathrm{PCO}_{2}$ & 36.4 & $\mathrm{mmHg}$ & $35-45$ \\
$\mathrm{pO}_{2}$ & 84.6 & $\mathrm{mmHg}$ & $80-100$ \\
$\mathrm{HCO}_{3}$ & 26.5 & $\mathrm{Mmol} / \mathrm{L}$ & $21-28$ \\
$\mathrm{BE}$ & 2.6 & $\mathrm{Mmol} / \mathrm{L}$ & $-3-+3$ \\
$\mathrm{Sat}$ & 97 & $\%$ & $>95$ \\
\hline Before oxygenation: & Severe hypoxemia. After \\
oxygenation: Moderate Hypoxemia, Respiratory \\
Alkalosis partially compensated, tend to type I \\
respiratory failure
\end{tabular}

Based on data above, the patient was diagnosed with High Altitude Pulmonary Edema (HAPE) + Community Acquired Pneumonia Ps 138 RC V + Septic condition 
+ Metabolic Acidosis + ARDS. Patient was given treatment, and was admitted to intensive care unit, and was given oxygenation, starting from bagging, continued with NIV, and lastly using Jackson Reese, with target oxygen saturation more than $92 \%$ and blood gas analysis showing $\mathrm{PCO}_{2}$ less than 50 cum $\mathrm{PO}_{2}$ closing to 100 . The patient was also given meropenem 3x1 gram, furosemid $3 \times 20 \mathrm{mg}$, NAC 3x200mg, Captopril 3x25mg, nebul combivent $3 x /$ day.

\section{Discussion}

In this case was reported, a 23-years-old male with High Altitude Pulmonary Edema (HAPE). Diagnosis established with anamnesis, physical examination, and other testings.

Anamnesis had indicated the patient's demography to be 23-years old male, in which based on epidemiology, the incidence rate was $3 \%$ on adult over 21 . In this case, the patient complained shortness of breath when climbing the Semeru mountain, in which in two days, patient had reached an altitude of 2700 mdpl. Based on studies, a series of gradual and integrated adaptation is needed in climbing places with high altitude, to adjust respiratory, cardiovascular, and hematology system. Rapid, non-gadual exposure to extreme altitudes can cause loss of conciousness and death. ${ }^{4}$
Anamnesis had also revealed the patient's history of climbing mountain while recovering from upper respiratory tract infection. Based on studies, upper respiratory tract infection before onset could lead to HAPE, due to being in substantially high altitude could worsen oxygen deficiency. ${ }^{1}$

Initial physical examination after evacuation, based on referral form issued by Sumber Sentosa Hospital, indicated the patient's temperature to be 38.9 ? $\mathrm{C}$, his heart rate is $122 \mathrm{x} / \mathrm{min}$, respiratory rate is $38 \mathrm{x} / \mathrm{min}$, and oxygen saturation is $46-49 \%$ with NRBM 10 lpm, and had also indicated rhonchi in all of lung area. Based on literatures, early stages of HAPE only shows mild symptoms such as: headache, dizziness, palpitations, insomnia, anorexia, an nausea. Pulmonary auscultation may show normal results, but X-Ray examination will reveal typical infiltrated shadow. Fevers are usually not found in early HAPE, but several patients show mild fever and cold intolerance. $^{1}$

Laboratory examination showed increase in leukocyte and neutrophil. Based on literatures, Leukocyte count is typically mildly increased; about $40 \%$ patients have a count over $1000 / \mathrm{mm}^{3}$. The neutrophilic granulocyte count also increases mildly. Both parameter rose indicated concurrent 
infection. ${ }^{1}$ Chest X-Ray indicated wide, irregular infiltrate in both sides of the lung, improved with oxygenation. ${ }^{4}$ Blood Gas Analysis showed increased $\mathrm{PaO}_{2}$ and low oxygen saturation, this indicating hypocarbia, severe hypoxemia, acidosis metabolic, type I respiratory failure. These findings corresponded literatures stating that blood gas analysis examination may show hypocarbia, severe hypoxemia, metabolic acidosis, and type I respiratory failure. ${ }^{1}$

Therapeutic approach in the patients is to immediately descend from altitude, give the patients warmth and let the patient rest. Oxygenation is also to be given as reccomended by literatures.$^{4}$ After initial treatment from Sumber Sentosa hospital, patients thus referred to Dr. Saiful Anwar Hospital. Patient thus admitted to intensive care unit for 4 days, and his condition improved as he was able to carry out his usual activites. Because the patient immediately descended from high altitude and was given prompt teatmen and oxygenation. $^{4}$

The patient was also given nebulization, ie. combivent. This is in accordance to literatures stating that salbutamol, $\beta 2$ receptor stimulant, could be given via inhalation starting from a day before high altitude exposure, $125 \mathrm{~g} /$ dose, 2 doses / day. Continued 2-3 days after high altitude exposure. $^{1}$

This patient was also given antibiotic, i.e. meropenem. Based on literatures, HAPE was said to be aggravated by lung infection. When two diseases occur together, each aggravates the other, as the condition becomes uncontrollable. In treating HAPE, wide spectrum antibiotic is usually given to prevent and treat infection. ${ }^{1}$

\section{Reference}

1. Qiquan Z, Yongjun L. High Altitude Pulmonary Edema. LUNG DISEASES-SELECTED STATE OF THE ART REVIEWS. 2012 Mar 2:539.

2. Bärtsch P, Swenson ER. Acute highaltitude illnesses. New England Journal of Medicine. 2013 Jun 13;368(24):2294-302.

3. Stream JO, Grissom CK. Update on high-altitude pulmonary edema: pathogenesis, prevention, and treatment. Wilderness \& environmental medicine. 2008 Dec 1;19(4):293-303.

4. Adams J. Rosen's Emergency Medicine-Concepts and Clinical Practice, 2-Volume Set, Expert Consult Premium Edition-Enhanced Online Features and Print, 7: Rosen's Emergency Medicine-Concepts and Clinical Practice, 2-Volume Set. Elsevier Health Sciences; 2010. 